\title{
The Experimental Research of Glass Multilayer Columns with a Central Compression
}

\author{
Mykhailo Surmai, Roman Tkach, Vasylyna Hula, Roman Kozak \\ Department of Building Construction and Bridges, Lviv Polytechnic National University, \\ Ukraine, Lviv, S. Bandery str., 12, E-mail: roman7tkach@gmail.com
}

The possibility of using structural building structures from a glass triplex has been discovered. The experimental tests of glass multilayer columns with vertical arrangement of layers have been introduced. The results of experiments have been obtained.

Keywords - laminated glass column/glass multilayer column, triplex, layer glass.

\section{Introduction}

Modern architecture and interior design introduce new forms and styles, the implementation of which along with the usage of particular materials is rather challenging task. The glass structures have become very popular. They are more often used not only as a fencing structure. The usual glass usage does not fully reveal its potential, and the current trend of using glass as an element of supporting structures makes it dramatically necessary to study its properties.

The main disadvantage of using ordinary glass is the fragile nature of its destruction, that is, it is collapsing instantly. Triplex technology is used to avoid such an effect: the glass is interconnected into several layers by means of a polymer film. The material of the film is an elastomer (a polymer with highly elastic properties in a wide temperature range), which allows to restrain parts of the fragments of glass structures, makes them plastic within the bonding plane, increases their reliability by preventing the instantaneous spread of cracks into the depths of the section.

Due to the instantaneous destruction of glass, mechanical devices are ineffective, since in order to avoid damage to them, they are removed from the structure, therefore, it is impossible to obtain information on its further operation. It is recommended to use other research methods that allow to observe the destruction process. The best way to do it is to use the method of digital image correlation (hereinafter referred to as DIC) $[4,6]$. It is based on the comparison in the specialized software images of the surface of the prototype made at each pressure level. Such comparison allows to track the movement of each point on the surface of the sample and obtain information about the state of its deformation.

\section{The analysis of recent studies and publications}

The triplex glass in Ukraine is not very widespread today. It is used in manufacturing floor slabs or small width coverage, partitions, facade glazing or interior elements (tables, stands, etc.). The lack of a calculation methodology and normative documents on the design of supportive structures from a glass triplex increases their cost, since each project is individual and requires experimental studies.

Under the guidance of Professor Bohdan Demchyna, the test of glass multilayer columns [3] and floor slabs [1,2] was conducted at Lviv Polytechnic National University. In 2017, the study of glass multilayer columns on central compression took place. The DIC method was successfully applied within the experiments mentioned above.

\section{The purpose of paper}

The purpose of the study was to discover the deformability of glass multilayer columns at central compression using DIC; to compare the outcomes obtained with different methods of measuring deformability. 


\section{The layout of the main body}

To discover the strength and deformability of glass multilayer columns, the prototype samples of two series of non-pressed sheet glass M4 were provided (Table 1).

Table 1

The characteristics of the prototype samples

\begin{tabular}{|c|c|c|c|c|c|c|c|c|c|}
\hline \multirow[b]{2}{*}{ Series } & \multirow[b]{2}{*}{$\begin{array}{l}\text { Brand of } \\
\text { columns }\end{array}$} & \multirow[b]{2}{*}{$\begin{array}{l}\text { Section, } \\
\mathrm{mm}\end{array}$} & \multirow[b]{2}{*}{$\begin{array}{c}\text { Height, } \\
\text { mm }\end{array}$} & \multirow{2}{*}{$\begin{array}{c}\text { Quantity } \\
\text { of film } \\
\text { layers, } \\
\text { pc }\end{array}$} & \multirow{2}{*}{$\begin{array}{l}\text { Thickness } \\
\text { of one } \\
\text { layer of } \\
\text { glass, mm }\end{array}$} & \multicolumn{4}{|c|}{ Characteristics of glass } \\
\hline & & & & & & 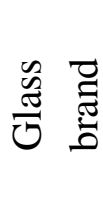 & 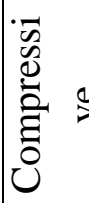 & 站 & 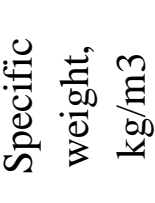 \\
\hline \multirow{2}{*}{ I } & KS-1.1 & $100 \times 70$ & \multirow{4}{*}{1000} & \multirow{3}{*}{1} & \multirow{4}{*}{10} & \multirow{4}{*}{ M4 } & \multirow{4}{*}{\multicolumn{2}{|c|}{700}} & \multirow{4}{*}{2500} \\
\hline & KS-1.2 & $120 \times 70$ & & & & & & & \\
\hline \multirow{2}{*}{ II } & КS-2.1 & $50 \times 70$ & & & & & & & \\
\hline & KS-2.2 & $50 \times 70$ & & 2 & & & & & \\
\hline
\end{tabular}

The samples are provided using triplexing technology (Fig. 1). Between layers of glass, an EVASAFE polymer film (Bridgestone, Japan) was applied, after which the columns were heated to the temperature of $130{ }^{\circ} \mathrm{C}$ and held for 30 minutes.

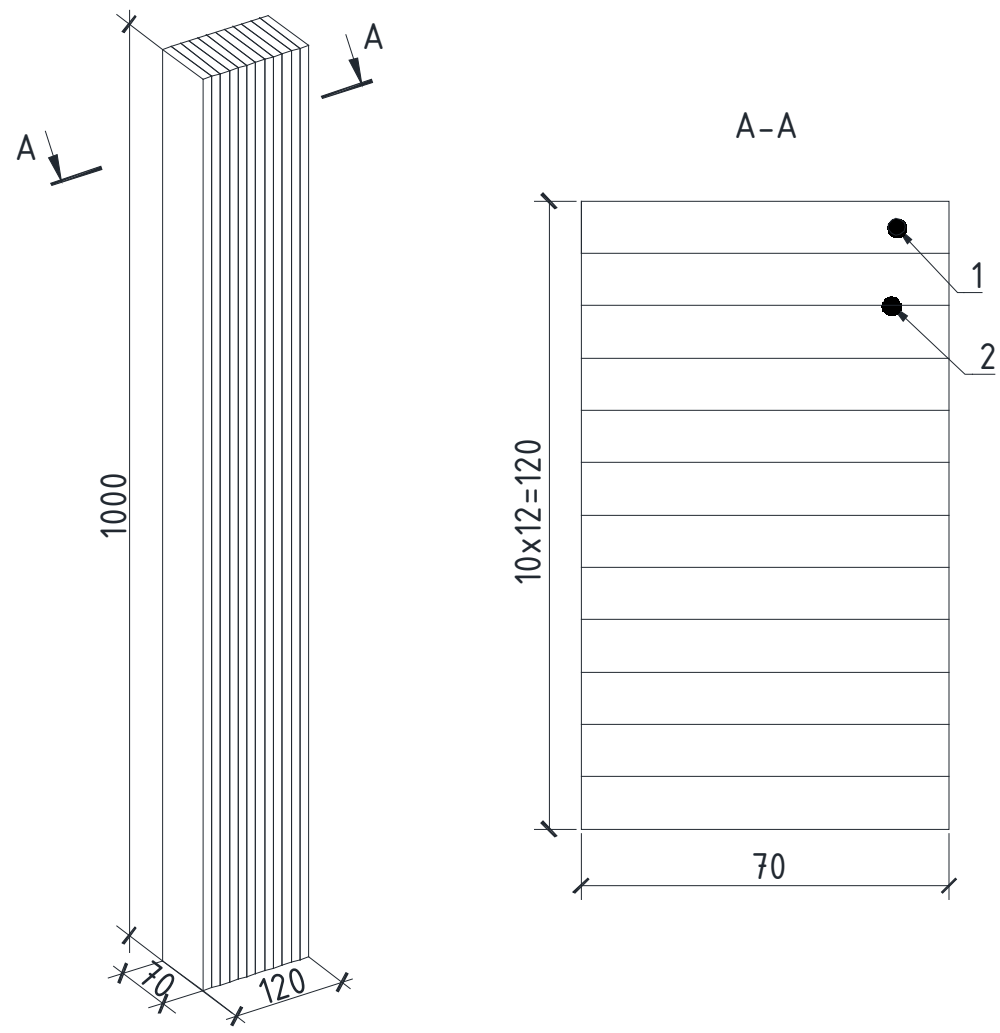

Fig. 1. The multilayer glass column of the brand KS-1.2

1 - glass coat; 2 - polymer film.

Experimental samples have been discovered as centrally compressed rods with rigidly fixed ends. In order to avoid local scrapping and breaking of glass in the bumps, the column was installed into metal boxes with a $6 \mathrm{~mm}$ thick plywood lining (Fig. 2). 

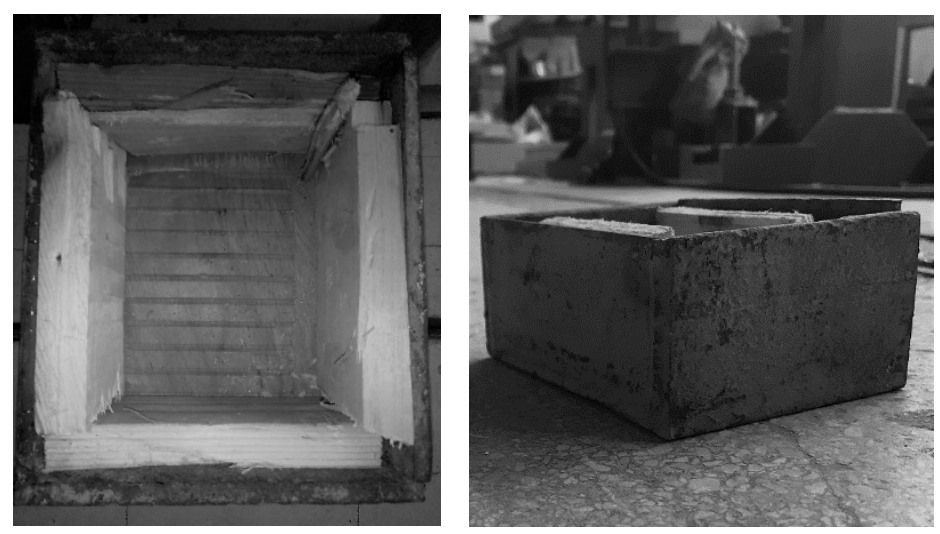

Fig.2. The metal boxes

The test was carried out on a hydraulic press PG-250, with the help of which an external pressure of $\mathrm{N}$ steps of $2.5 \mathrm{kN}$ was applied up to the destruction. The shutter speed at each load level was 10 minutes. The scheme of placing devices on the prototype is shown in Fig. 3. The testing sample 1 was located vertically between the crossings of the hydraulic press 4 and 5.

To measure longitudinal deformations, the clock-type micro-indicators 8, with a scale interval of 0,001 $\mathrm{mm}$ and a $200 \mathrm{~mm}$ basis, were used, and the digital image correlation method for which a surface 2 was prepared on each sample. To determine the bending and curvature of the column, the actinometers of Aistov 7 were used, with the scale interval of $0,01 \mathrm{~mm}$. After the application of $80 \%$ of the expected destructive pressure, all devices were removed. Measurement of deformations was provided only with the help of DIC.

The first cracking of the glass column KS-1.1 occurred under pressure $\mathrm{Nw}=650 \mathrm{kN}$ on the upper bearing area, and small cracks occurred on the lower part (Fig. 4). The complete destruction of the prototype of the brand KS-1.1 occurred under pressure $\mathrm{Nsr}=790 \mathrm{kN}$ in the middle of the height of the column from the occurrance of horizontal and transverse cracks.

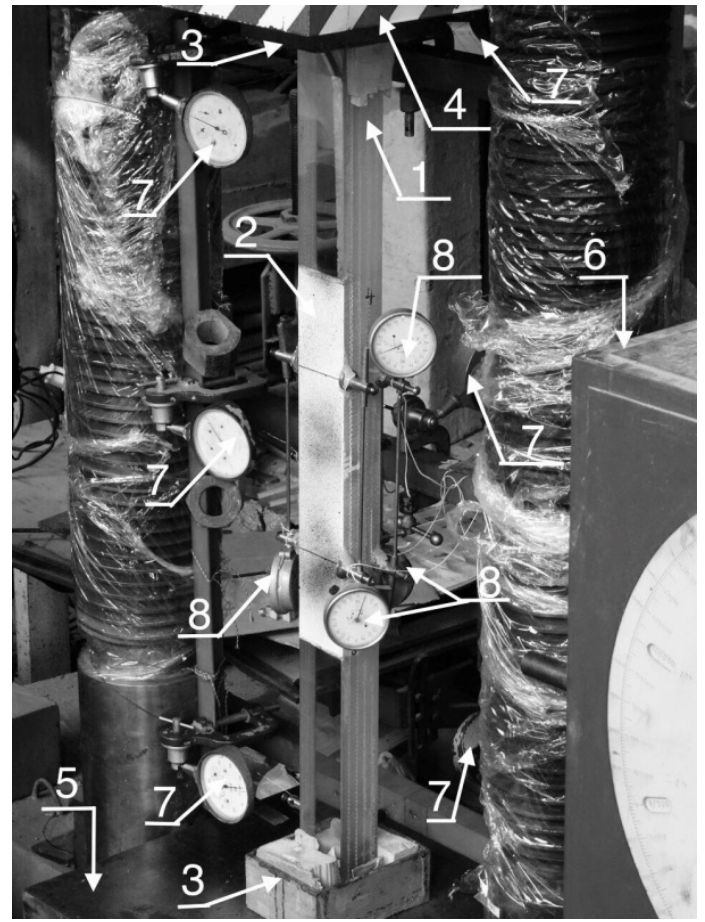

Fig. 3. The testing installation

1-test column; 2 - field for measurement of deformations with the help of DIC; 3 - metal boxes; 4 - traverse support; 5 - traverse load; 6 - hydraulic press PG-250; 7 - Aistov deflectometer; 8 - Clock type microdistrict. 
The first crack of the column brand KS-1.2 occured on the lower and upper supporting areas under pressure $\mathrm{Nw}=790 \mathrm{kN}$. The destruction occurred under pressure Nsr $=950 \mathrm{kN}$, also in the middle of the height of the column from the appearance of horizontal and transverse cracks. The destruction of the column occurred plastically with a visible bend in the plane perpendicular to the adhesive seams (Fig. 4.b.). The first shredding of the glass coat of the samples of the II series occurred under pressure $\mathrm{Nw}=175 \mathrm{kN}$ on the upper and lower supporting areas (Fig. 4).

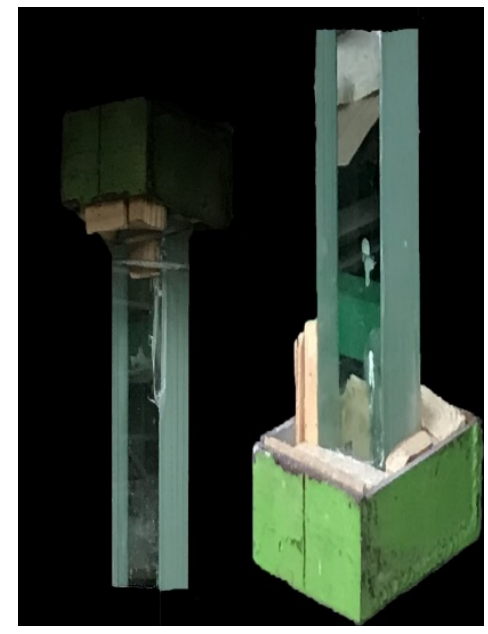

a)

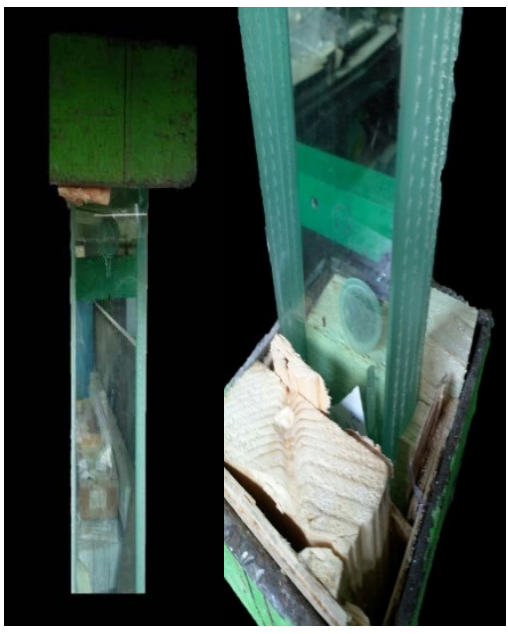

b)

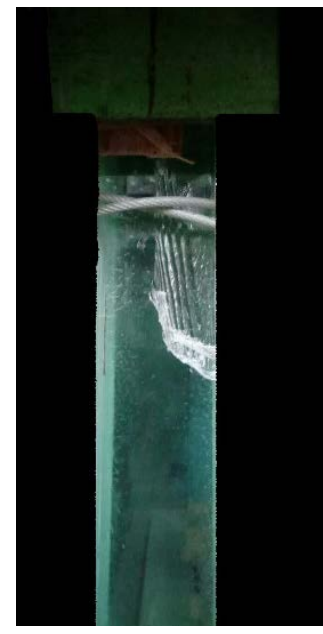

c)

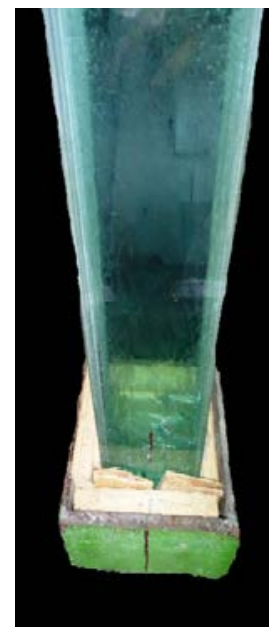

d)

Fig. 4. The supporting areas of the columns in case of cracks

a) columns of the brand KS-2.1; b) columns of the brand KS -2.2; c) top of the column of the brand KS -1.1; d) bottom of the column of the brand KS-1.1.

The complete destruction of the prototype of the brand KS-2.1 occurred at Nsr $=270 \mathrm{kN}$ in the middle of the height of the column due to the cracks. The collapse of the column of the brand KS-2.2 occurred at Nsr $=265 \mathrm{kN}$, also in the middle of the height of the column due to the cracks. The destruction of samples of both series was plastic. All the columns were destroyed with a visible bend in the plane perpendicular to the adhesive seams (Fig. 5).

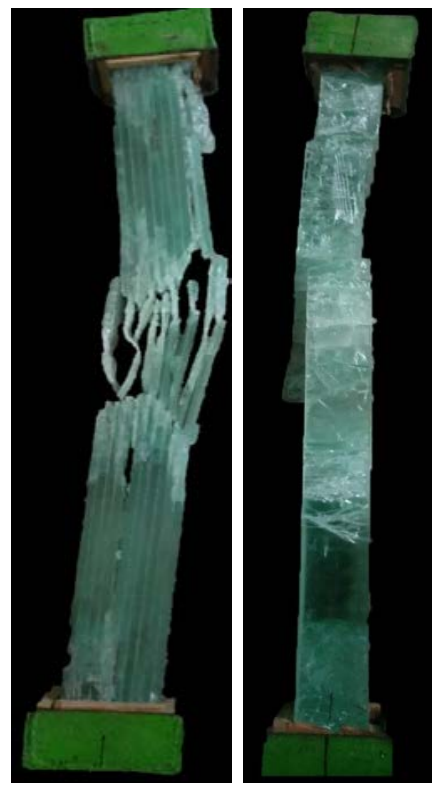

a)

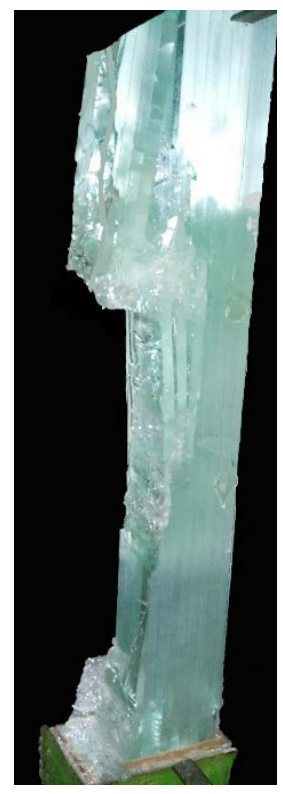

b)

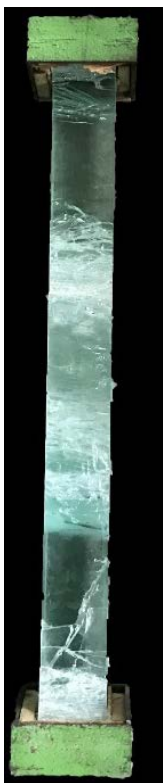

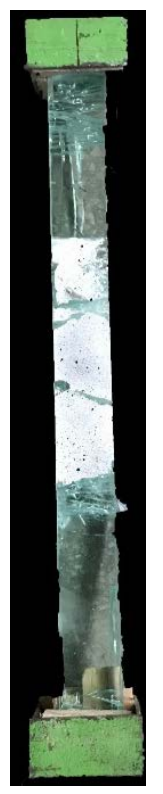

c)

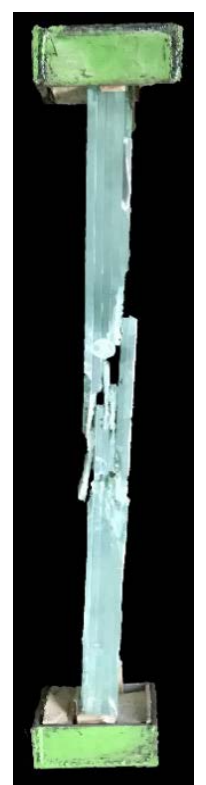

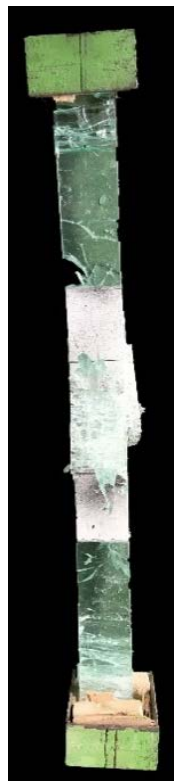

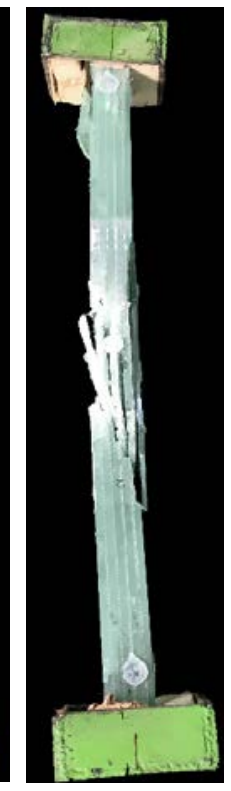

d)

Fig. 5. The nature of the destruction of prototype samples

a) columns of the brand $\mathrm{KS}-1.1$; b) columns of the brand $\mathrm{KS}-1.2$; c) columns of the brand $\mathrm{KS}-2.1$; d) columns of the brand $\mathrm{KS}-2.2$. 
After having analyzed the outvomes of the experiment, the assumption of the direct dependence of the magnitude of the destructive pressure on the square of the cross-section of the column was formulated (Table 2).

Table 2

\begin{tabular}{|c|c|c|c|c|}
\hline \multirow{2}{*}{ Series } & $\begin{array}{c}\text { Brand of } \\
\text { columns }\end{array}$ & $\begin{array}{c}\text { Square of cross- } \\
\text { section A, } \\
\mathrm{mm}, \mathrm{sm}^{2}\end{array}$ & $\begin{array}{c}\text { Destructive pressure } \\
\mathrm{N}_{\mathrm{cr}}, \mathrm{kH}\end{array}$ & $\begin{array}{c}\text { Destructive } \\
\text { tension } \sigma_{\mathrm{cr}}, \\
\mathrm{kH} / \mathrm{sm}^{2}\end{array}$ \\
\hline \multirow{2}{*}{ I } & KS-1.1 & 70 & 790 & 0,088 \\
\cline { 2 - 5 } & KS-1.2 & 84 & 950 & 0,088 \\
\hline \multirow{2}{*}{ II } & KS-2.1 & 35 & 270 & 0,129 \\
\cline { 2 - 5 } & KS-2.2 & 35 & 265 & 0,132 \\
\hline
\end{tabular}

The columns of the II series had the same geometric characteristics of the section, but differed in a different number of film layers. That is, the number of film layers within a multilayer glass column with vertical placement of glass layers does not significantly affect the bearing capacity of the column.

The analysis of the deformations of the columns of the II series showed similar results.

According to the results of the experimental studies, the graphs of the bends of both series of columns were constructed depending on the external pressure (Figures 6 and 7).

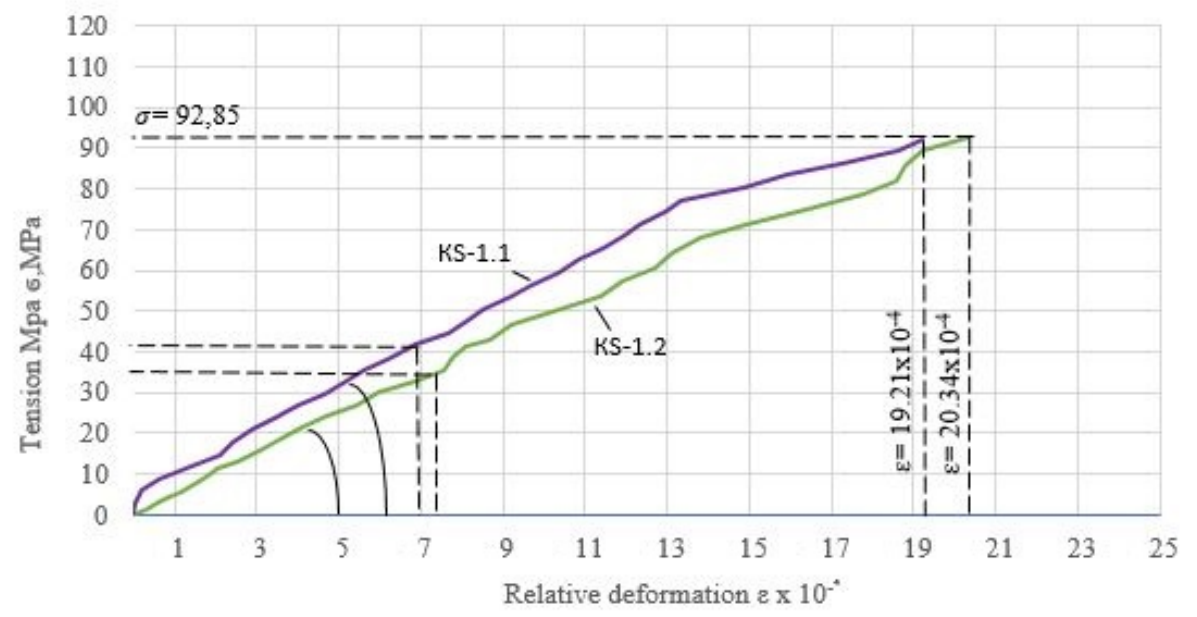

Fig. 6. The graph of the dependence of relative deformations on the tension of the columns of the I series.

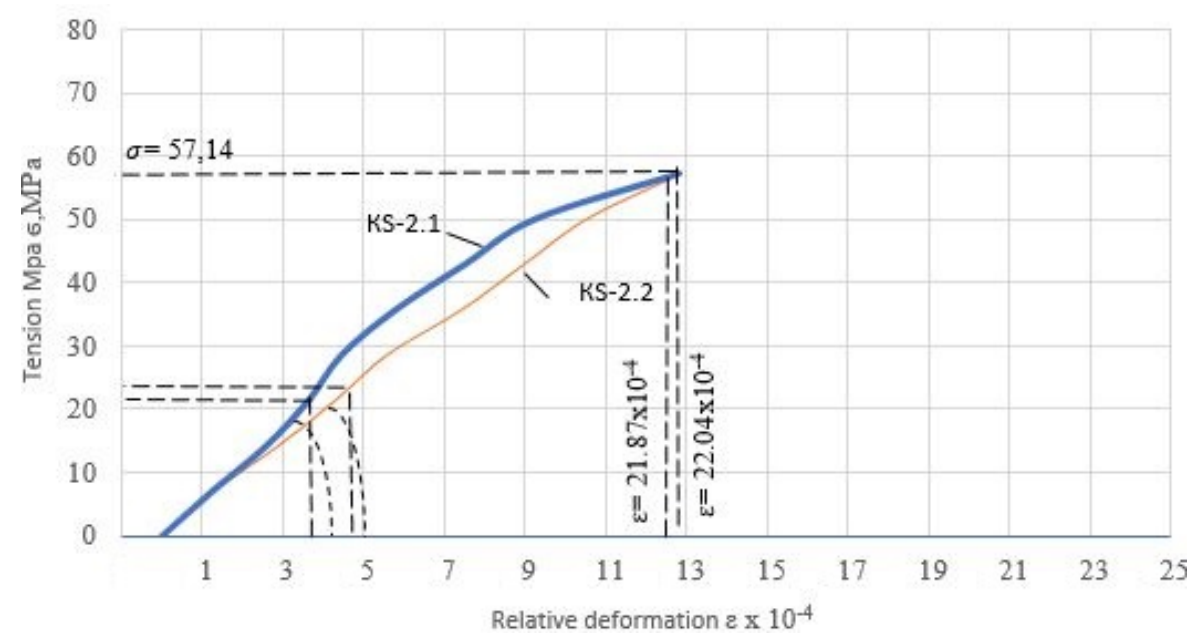

Figure 7. The graph of the dependence of relative deformations on the tension of the columns of the II series. 
After having analyzed the graph of the dependence of relative deformations on the tension, according to Hooke's law, the elastic modulus of the triplex glass E was obtained (Table 3).

Table 3

\begin{tabular}{|c|c|c|c|}
\hline \multirow{2}{*}{ Series } & $\begin{array}{c}\text { Brand of } \\
\text { columns }\end{array}$ & $\begin{array}{c}\text { Maximum pressure } \sigma, \\
\mathrm{MPa}\end{array}$ & $\begin{array}{c}\text { Modulus of elasticity of } \\
\text { triplex glass E, GPa }\end{array}$ \\
\hline \multirow{2}{*}{ I } & KS-1.1 & 112,86 & 47,29 \\
\cline { 2 - 4 } & KS-1.2 & 113,09 & 48,35 \\
\hline \multirow{2}{*}{ II } & KS-2.1 & 77,14 & 49,81 \\
\cline { 2 - 4 } & KS-2.2 & 75,71 & 51,10 \\
\hline
\end{tabular}

The modulus of elasticity of triplex glass according to the obtained results of the conducted research varies within 47,29-51,10 GPa, whereas the modulus of elasticity of a sheet glass is 70 GPa.

\section{Conclusion}

1. The experimental study of glass multilayer columns on the central compression has been conducted.

2. The destructive values of presssure and tension have been established.

3. The value of the modulus of elasticity of the triplex glass has been obtained.

\section{References}

[1] Osadchuk T. Yu. The Study of the Strength of Multilayer Glass Slabs Performing on the Bend from a Concentrated Pressure by a Stamp / T. Yu. Osadchuk, B. H. Demchyna // Building Construction Production: Interdepartmental Scientific and Technical Collection. - K.: RDICP, 2016. - № 60/2016. - P. 58-63.

[2] Demchyna B. H., Osadchuk T. Yu. The Study of Deformation of Multilayer Glass Plates with the help of Correlation of Digital Images // Communal Economy of Cities. Series: Engineering and Architecture. KhNUCE, Kharkiv - 2017. - Vol.134. - P. 153-163.

[3] Demchyna B. H., Cherevko M.V. The Study of Strength and Deformability of Glass Columns with Vertical Placement of Layers // Journal of Lviv Polytechnic National University: The Theory and Practice of Building Construction. - Lviv, 2015. - №823. P.113-116.

[4] Kovalchyk Ya. I. Prospects for the Usage of the Method of Digital Image Correlation for the Study of Building Structures / Ya. I. Kovalchyk // Collection of Scientific Works of the Poltava National Technical University Named After Y. Kondratyuk: Sectoral Engineering, Construction. - 2012. - Issue 5. - P. 92-100.

[5] Digital Image Correlation (DIC) Measurement Principles [Electronic resource]. - Mode of access: http://www.dantecdynamics.com/measurement-principles-of-dic.

[6] Berezin V. B. The Study of the Field of Deformation of the Flat Surface of Samples of Materials by the Method of Correlation of Digital Images. (Static Pressure) / V. B. Berezin, M. H. Chausov // Technical Diagnostics and Non-destructive Control. - 2011. - № 2. - P. 15-20.

[7] Helfrick M. An Investigation of 3D Digital Image Correlation for Structural Health Monitoring and Vibration Measurement / M. Helfrick // ProQuest. - 2008. - 192 p.

[8] Yoneyama S. Digital Image Correlation / S. Yoneyama, G. Murasawa // In Experimental Mechanics, Encyclopedia of Life Support Systems (EOLSS), Eolss Publishers, Oxford, UK, 2009.

[9] Pickerd V. Optimisation and Validation of the ARAMIS Digital Image Correlation System for use in Large-scale High Strain-rate Events / V. Pickerd // DSTO Defence Science and Technology Organisation. - 2013. - 32 p. 